\title{
Long segment 3D double inversion recovery (DIR) hypersignal on MRI in glaucomatous optic neuropathy
}

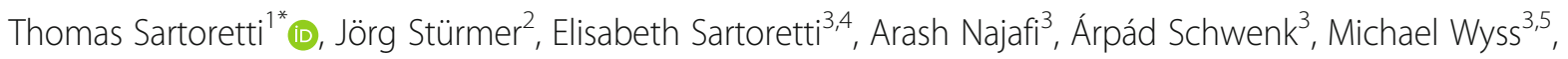
Christoph Binkert ${ }^{3,4}$ and Sabine Sartoretti-Schefer ${ }^{3,4}$

\begin{abstract}
Background: In this retrospective study the relationship between intraocular pressure (IOP), retinal nerve fiber layer (RNFL) thickness and pathologic hypersignal in optic nerve segments on 3D double inversion recovery (DIR) MR sequence in 21 patients with proven glaucoma of different origin was evaluated.

Methods: All patients were examined on a 3 T MR Philips ${ }^{\circledast}$ scanner. Pathologic optic nerve DIR hypersignal was determined in four different nerve segments. IOP was measured in $\mathrm{mmHg}$ by applanation tonometry. RNFL thickness was measured in $\mu \mathrm{m}$ with optical coherence tomography (OCT Heidelberg Engineering Spectralis ${ }^{\circledast}$ apparatus). Wilcoxon rank sum tests, student's t-tests and (multivariate) linear regression models were appied.

Results: 3D DIR hypersignal was present in 17 (41.5\%) optic nerves. 3D DIR hypersignal was not related to ischemic or demyelinating optic nerve pathology but was associated with increased IOP (19.8 [24-18]; versus 15.45; [18.85-13.75] $\mathrm{mmHg} ; p=0.008)$ and decreased RNFL thickness $(61.06 \pm 12.1$ versus $82.5 \pm 21.6 \mu \mathrm{m} ; p<0.001)$ in comparison to optic nerves of glaucoma patients without DIR hypersignal. Specifically, presence of DIR hypersignal in optic nerves in at least one optic nerve segment lowered RNFL thickness on average by $17.54 \mu \mathrm{m}(p=0.005)$ in comparison to optic nerves without DIR hypersignal.

Conclusions: In patients with glaucomatous optic neuropathy (GON) and pathologic optic nerve DIR hypersignal, significantly increased IOP and significantly decreased RNFL thickness values are present. DIR hypersignal seems to be a marker for disease severity in GON related to decreased RNFL thickness and may thus represent long-segment severe axonal degeneration in optic nerves in patients with GON. Venous congestion and edema within the optic nerve related to high IOP may contribute to the DIR hypersignal as well.
\end{abstract}

Keywords: Glaucoma, Glaucomatous optic neuropathy, Double inversion recovery (DIR) MR sequence, DIR hypersignal, Optical coherence tomography $(\mathrm{OCT})$

\section{Background}

Glaucoma comprises a group of irreversible and progressive eye diseases that result in damage to the optic nerve [1-3] due to decay of retinal ganglion cells (RGCs) and degeneration of their axons [4-7].The damage to the optic nerve is caused by mechanical and vascular factors together with impairment arising by compartimentalization of the cerebrospinal fluid around the optic nerve

\footnotetext{
* Correspondence: sarthoma@student.ethz.ch

'Laboratory of Translational Nutrition Biology, Department of Health Sciences and Technology, 8603 ETH Zürich, Schwerzenbach, Switzerland

Full list of author information is available at the end of the article
}

[8-14] whereas the intraocular pressure (IOP) is the main critical causative risk factor [8]. The neural damage is enhanced by additional risk factors as genetic factors, increased patient age, family history of glaucoma, thin corneal thickness, low ocular systolic / diastolic pressure or low mean ocular perfusion pressure and obstructive sleep apnoea syndrome [9-13].

The damage to the RGCs and axons is confirmed by thinning of the peripapillary retinal nerve fiber layer (RNFL) thickness that is quantitatively measurable by optical coherence tomography (OCT) [15-19].

(c) The Author(s). 2019 Open Access This article is distributed under the terms of the Creative Commons Attribution 4.0 International License (http://creativecommons.org/licenses/by/4.0/), which permits unrestricted use, distribution, and 
Usually glaucoma is diagnosed by clinical and ophthalmologic examinations (examination of the visual field, measurements of the intraocular pressure, RNFL thickness measurements etc.) and MRI of the optic system is not considered necessary for diagnosis. In patients with atypical and asymmetric visual field defects, however, where the diagnosis of glaucoma is not easily achieved, an additional MR examination of brain and orbits is added to exclude ischemic and demyelinating pathology [20-23].

In several of these patients unexpectedly pathologic long segment 3D Double Inversion Recovery (3D DIR) hypersignal of multiple optic nerve segments was observed that was not related to ischemic or demyelinating optic nerve pathology. Thus, in our retrospective study we wondered if there was a relationship between IOP and RNFL thickness values (representing disease severity) and pathologic DIR hypersignal in these patients.

\section{Methods}

\section{Patient selection}

21 glaucoma patients (18 open-angle glaucoma, 2 angleclosure glaucoma, 1 normal tension glaucoma, either uni- or bilateral presentation) who were given a dedicated MRI examination of brain and orbits were identified (41 eyes were included in the analysis). Patients (10 males, 11 females) had a mean age of 64 years (meals: 51-80 years; females: $45-83$ years). All patients used 1 to 4 different drugs for IOP control. Glaucoma was diagnosed based on ophthalmologic examinations, on the average intraocular pressure (IOP) with 2-4 pressure measurements performed by applanation tonometry within 1 month before MRI and with a pathologic IOP of more than $21 \mathrm{mmHg}$, on OCT measurements and on visual field measurements (OCTOPUS perimetry using dynamic strategy G2 program with analysis of mean deficit or Goldman perimetry) [19].

Atypical and asymmetric visual field defects, not in accordance with the classical appearance of a glaucomatous optic papilla on fundoscopy, resulted in the decision of the ophthalmologist to perform MRI examination in all these patients in order to exclude additional vascular and demyelinating orbital or cerebral pathology. Toxic, metabolic, nutritional and hereditary optic neuropathy were excluded by laboratory and clinical evaluation.

\section{Ophthalmologic examination}

The thickness of the peripapillary RNFL in 6 sectors at the optic nerve head $(\mathrm{ONH})$ was determined by OCT on a Heidelberg Engineering Spectralis ${ }^{\circ}$ apparatus and the arithmetic mean determined the resulting RNFL thickness value [19]. Highly pathologic values correspond to a RNFL thickness of 40 to $76 \mu \mathrm{m}$, pathologic values to a thickness of 77 to $85 \mu \mathrm{m}$ and normal values to a thickness of over $86 \mu \mathrm{m}$ (data supplied by Heidelberg Engineering ${ }^{\circledR}$ ). OCT measurements were obtained within 2 months before or after the MRI examination.

\section{MRI examination}

All MRI examinations were obtained on a $3 \mathrm{~T}$ MR Achieva Philips ${ }^{\circ}$ scanner. Beside other sequences as 3D fluid attenuated inversion recovery (FLAIR), T2 weighted (w) turbo spin echo (TSE) and diffusion weighted (DWI) sequences a sagittal 3D DIR sequence (sequence parameters depicted in Table 1) with reconstruction of coronal and transverse images (slice thickness of $1 \mathrm{~mm}$ ) was acquired and these sequences helped to exclude ischemic disease. Periventricular, juxtacortical and infratentorial lesions were absent on 3D FLAIR and on 3D DIR [20-22] and thus demyelinating disease could be excluded based on McDonald criteria for the diagnosis of multiple sclerosis [22]. Ischemic optic neuropathy could be excluded because of missing diffusion restriction on DWI and because of missing history of acute vision loss.

Pathologic DIR hypersignal of optic nerve segments (i.e. retrobulbar, canalicular, prechiasmatic, chiasmatic segments) was rated in comparison with the signal intensity of the ipsilateral lateral rectus muscle [23]. Longsegment DIR hypersignal was defined as hypersignal in at least 2 nerve segments. Pathologic DIR hypersignal was confirmed on corresponding coronal T2w STIR images or on the T2w m-Dixon TSE sequence. Rating was performed in consensus by two board certified neuroradiologist with 30 years and 5 years of experience.

\section{Statistical analysis}

The Kolmogorov-Smirnov test was used to check normality of data. Wilcoxon rank sum tests or student's t-tests

Table 1 Imaging parameters of the 3D DIR sequence on 3 T MR Achieva $^{\circledR}$ Philips

\begin{tabular}{ll}
\hline & 3D double inversion recovery DIR \\
\hline Acquisition mode & 3D turbo spin echo \\
Acquisition plane & sagittal \\
Coverage & whole head \\
Reconstructions, slice thickness & coronal, $2 \mathrm{~mm}$ \\
TR / TE & $5500 \mathrm{~ms} / 246 \mathrm{~ms}$ \\
TI & $2550 \mathrm{~ms} / 450 \mathrm{~ms}$ \\
FOV & $250 \times 250 \times 195 \mathrm{~mm}$ \\
Matrix & $240 \times 240 \times 310$ \\
Acquired voxel size & $1.2 \times 1.2 \times 0.65 \mathrm{~mm}$ \\
Number of slices & 300 \\
Fat suppression & spectral presaturation with \\
Number of excitations & inversion recovery SPIR \\
Acquisition time & 2 \\
\hline
\end{tabular}


and (multivariate) linear regression models were then applied to test the relationship between hypersignal, RNFL thickness and IOP. Age was included in the regression models to account for a physiological decrease in RNFL thickness with increasing age. Significance was set at $p \leq$ 0.05 . Data is presented either as mean \pm standard deviation (SD) in case of normally distributed data or median;[interquartile range (IQR)] in case of non-normally distributed data. For statistical analysis IBM SPSS Statistics, Version 25.0 was used.

\section{Results}

In 17 (41.5\%) of 41 optic nerves DIR hypersignal in at least one optic nerve segment was present (Figs. 1 and 2). DIR hypersignal was observed in 1 nerve segment in $5.9 \%$, in 2 segments in $35.3 \%$, in 3 segments in $52.9 \%$ and in 4 segments in $5.9 \%$ of these 17 nerves as shown in Fig. and Fig. 2. Thus long-segment DIR hypersignal was present in 94.1\% of DIR hyperintense optic nerves.

There was no significant relationship between the number of segments displaying hypersignal and IOP or RNFL thickness values.

Presence of DIR hypersignal in optic nerves in at least one segment lowered RNFL thickness by $17.54 \mu \mathrm{m}(p=$ 0.005 ) in comparison to optic nerves without DIR hypersignal. Optic nerves with DIR hypersignal had significantly lower RNFL thickness values $(61.06 \pm 12.1$ versus
$82.5 \pm 21.6 \mu \mathrm{m} ; p<0.001)$ and significantly higher IOP values $(19.8$ [24-18]; versus 15.45 ; [18.85-13.75] mmHg; $p=0.008)$ as shown in Fig. 3. When considering all optic nerves higher IOP values could be associated with lower RNFL thickness values $(r=-0.36, p=0.02)$ as shown in Fig. 4. The data used for this analysis is available in the supplementary material.

\section{Discussion}

For the first time, we report on pathologic long-segment 3D DIR hypersignal in optic nerves affected by GON in glaucoma patients associated with significantly decreased RNFL thickness values and significantly increased IOP and not associated with demyelinating or ischemic optic neuropathy. It is known from a previous study that normal and healthy optic nerves always present with a hypointense signal compared to the signal intensity of ipsilateral lateral rectus muscle [23] and hypersignal on DIR is always pathologic [23].

An increase in IOP with or without associated decreased ocular perfusion and with changes in perioptic CSF pressure and protein / neurotoxic molecule content due to compartimentalization of the perioptic CSF spaces as well as additional factors (as for example patient age) might be a trigger for a cascade of events leading to damage of the RGC cells and axons with decreased RNFL thickness [8-14, 19, 24-30]. Finally a

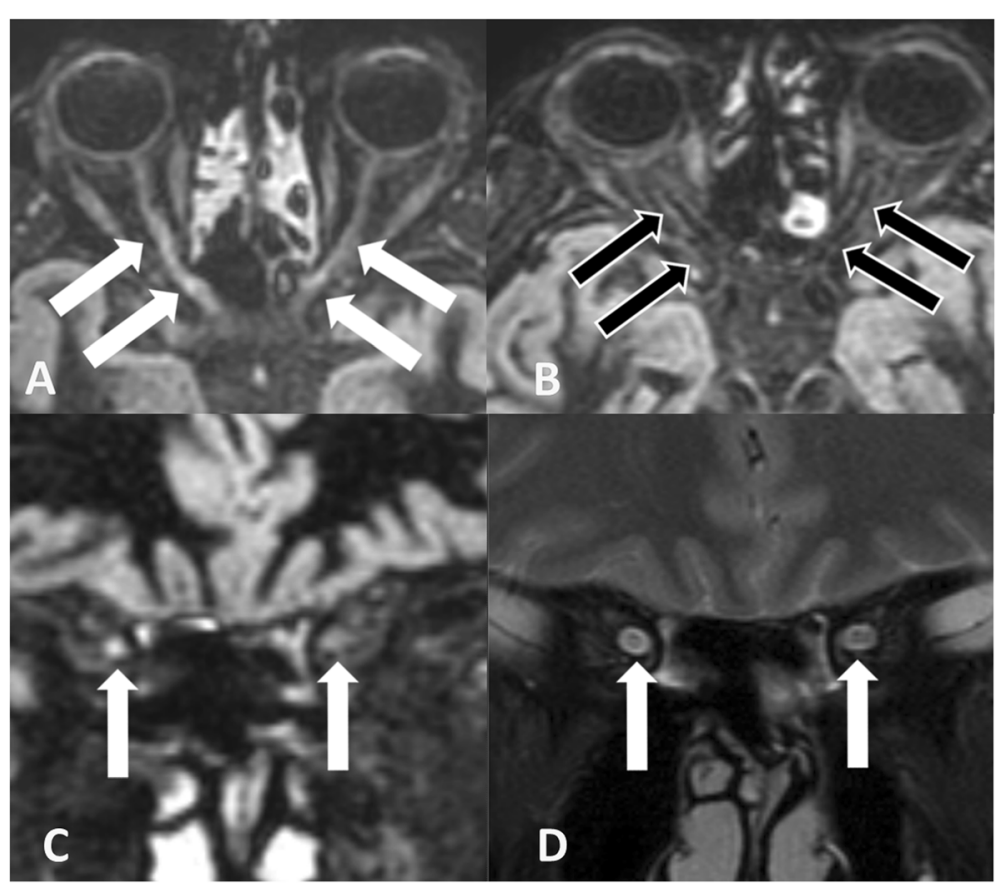

Fig. 1 Bilateral DIR hypersignal in retrobulbar and canalicular optic nerve segments (white arrows on the transverse image reconstruction in a and on the coronal image reconstruction in c) compared to normal DIR hypointense retrobulbar and canalicular optic nerve segments (black arrows with white rim on transverse image reconstructions in $\mathbf{b}$ ). For comparison hypersignal in the retrobulbar segment is also shown on the coronal T2w m-Dixon turbo spin echo image (white arrows in d) 


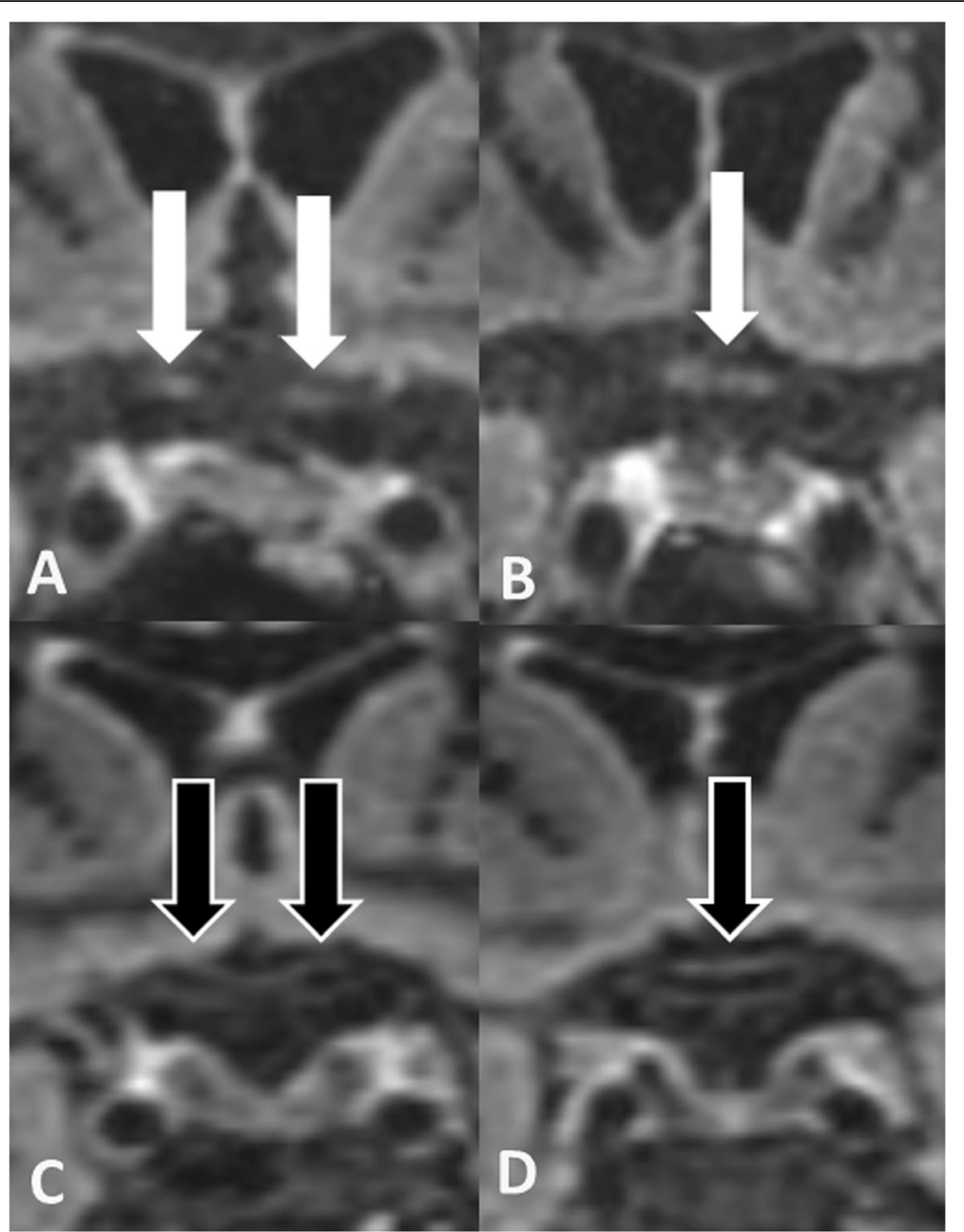

Fig. 2 Coronal DIR reconstructions presenting with bilateral DIR hypersignal in prechiasmatic (a) and chiasmatic (b) optic nerve segments (white arrows) compared to normal DIR hypointense prechiasmatic (c) and chiasmatic (d) optic nerve segments (black arrows with white rims)

long-segment neuropathy with antegrade and retrograde axonal degeneration and disruption of axonal transport from the $\mathrm{ONH}$ to the lateral geniculate ganglion $[5-7,26]$ and with RNFL thickness loss [26-30] is the end result of the glaucomatous nerve damage. Axonal degeneration causes a hyperintense signal on T2w MR images at the nerve lesion site and distal to it [31] and thus may correspond to the long-segment DIR hypersignal observed in our patients. Most probably the diffuse $\mathrm{T} 2$ hyperintense signal of optic nerves described in a previous study and attributed to intraneural edema associated with acutely increased intraocular pressure may represent the same finding [32] as was obtained as DIR hypersignal in our study. The recently observed focal $\mathrm{T} 2$ hyperintensity of the optic nerve heads related to GON, but without associated signal intensity change of the entire nerve [33] may be part of the same imaging spectrum with DIR hypersignal of the entire nerve in GON.
Thus the clinically relevant findings of this study are that long-segment DIR hypersignal in GON should not be mistaken for the typical short-segment subclinical optic nerve demyelination usually occurring in the retrobulbar nerve segment in patients with multiple sclerosis [23].

Furthermore DIR hypersignal seems to reflect disease severity due to its association with significantly decreased RNFL thickness values and increased IOP values and may thus be an interesting clinical diagnostic tool. This should be reviewed systematically in a future study.

There are several possible restrictions to the results of our study:

1. OCT and IOP measurements were not performed on the same day as the MR examination.

2. Only selected patients were sent to MR examination in order to exclude additional pathology beside glaucoma introducing a selection bias. 


\section{Intraocular Pressure (IOP)}

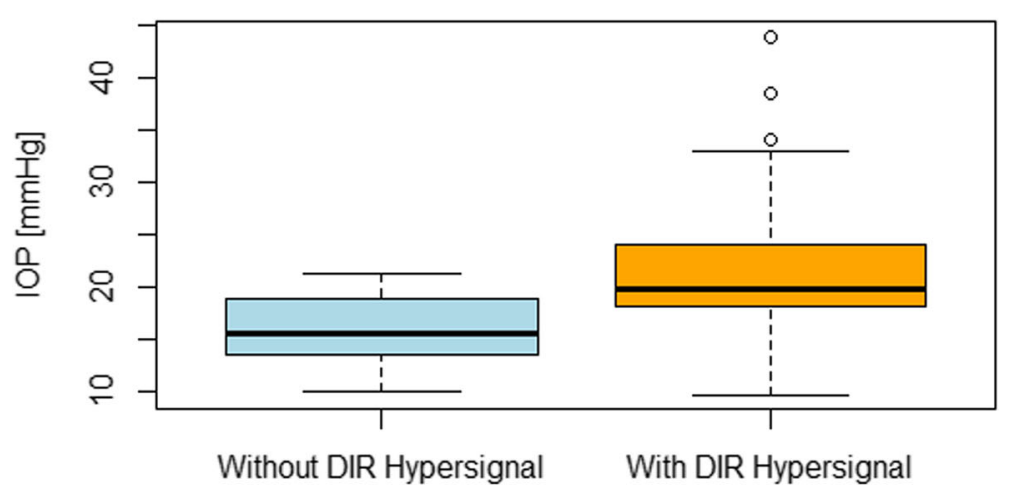

Retinal Nerve Fiber Layer Thickness (RNFL)

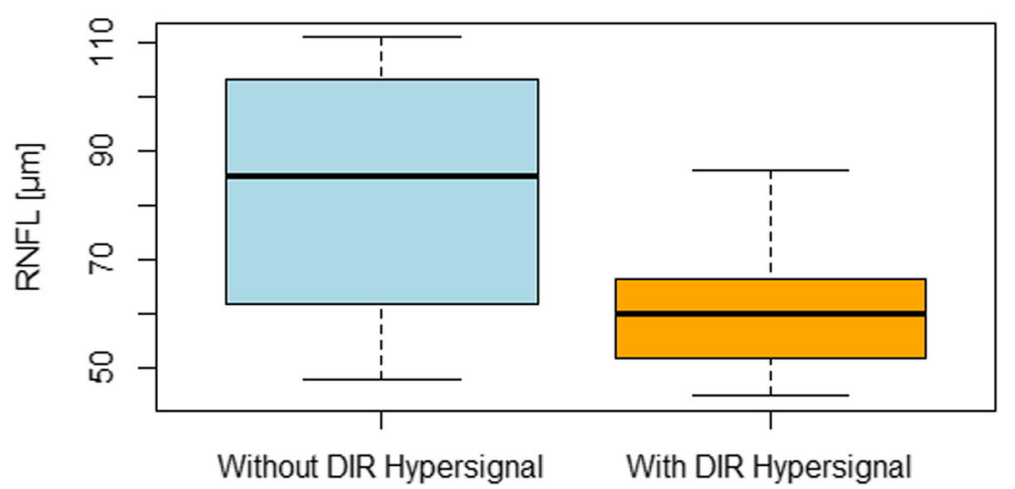

Fig. 3 Upper boxplot diagram depicting intraocular pressure data. Lower boxplot diagram depicting RNFL thickness dataThe median is depicted as a prominent line in the middle of the box, the mean as a cross and 0.75 respectively 0.25 quantiles as the upper and lower limits of the box.

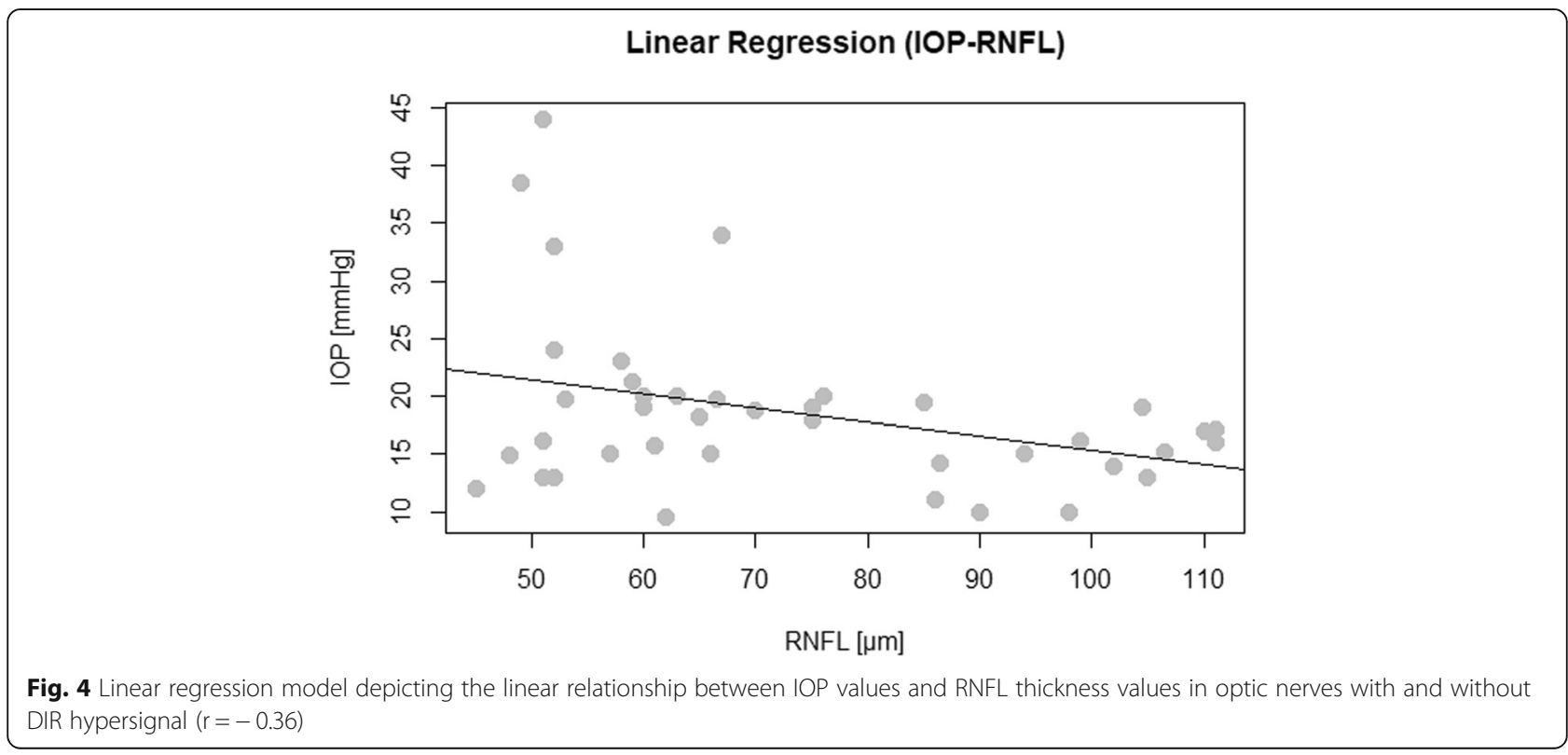


3. The patient population was not homogeneous. Not only patients with open angle glaucoma, but also patients with NTG and with closed-angle glaucoma were included. This may have influenced IOP measurements.

4. Our population size is quite small as only few patients with GON are given a dedicated MRI examination. Further studies are needed to confirm our findings.

5. Every eye was evaluated separately because glaucomatous optic neuropathy can present unilaterally or bilaterally with varying degrees of severity in case of bilateral presentation. Therefore a possible correlation between both eyes in a patient potentially influencing our results was not taken into account.

6. RNFL thickness values were used as the primary marker for disease severity. However, it has to be acknowledged that other metrics such as visual field index VFI and visual field mean deviation MD are also important metrics for analysis of the disease severity. However the association between DIR hypersignal and VFI and MD was not systematically evaluated in our patients.

\section{Conclusion}

Significantly increased IOP and significantly decreased RNFL thickness values were present in patients with glaucomatous optic neuropathy (GON) and pathologic optic nerve DIR hypersignal. DIR hypersignal seems to be a marker for disease severity in GON related to decreased RNFL thickness and may thus represent longsegment severe axonal degeneration in optic nerves in patients with GON. Venous congestion and edema within the optic nerve related to high IOP may contribute to the DIR hypersignal as well. Most importantly, long-segment DIR hypersignal in GON should not be mistaken for the typical short-segment subclinical optic nerve demyelination usually occurring in the retrobulbar nerve segment in patients with multiple sclerosis.

\section{Supplementary information}

Supplementary information accompanies this paper at https://doi.org/10. 1186/s12886-019-1273-0.

Additional file 1. contains data named "study data". The study data contains all data used in this study, such as IOP and RNFL values.

\section{Abbreviations}

Cl: Confidence interval; DIR: Double inversion recovery; GON: Glaucomatous optic neuropathy; IOP: Intraocular pressure; MD: Mean deficit; NTG: Normal tension glaucoma; OCT: Optical coherence tomography; ONH: Optic nerve head; RGC: Retinal ganglion cells; RNFL: Peripapillary retinal nerve fiber layer; SD: Standard deviation

\section{Acknowledgements}

Not applicable.

\section{Authors'contributions}

TS: conception, design, collecting data, analysis and interpretation of data, drafting the article, JS: collecting data, drafting the article, revising the article, analysis and interpretation of data. ES: drafting the article, revising the article. AN: revising the article. AS: collecting data, revising the article. MW: drafting the article, revising the article, analysis and interpretation of data. CB: revising the article. SS: conception, design, drafting the article, revising the article, analysis and interpretation of data. All authors read and approved the final revision.

\section{Funding}

No funding was received for this study. However, financial support for open access publication fees was granted by ETH Zürich, Switzerland.

\section{Availability of data and materials}

The dataset used and analysed during the current study are available from the corresponding author on reasonable request.

\section{Ethics approval and consent to participate}

All procedures performed in studies involving human participants were in accordance with the ethical standard of the institutional and / or national research committee and with the 1964 Helsinki declaration and its later amendments or comparable ethical standards.

This retrospective study with the number Basec 2016-01396 was approved by the Institutional Review Board "Kantonale Ethikkommision Zürich" on 26th September 2016. Additional informed consent and informed consent to publish was waived by the Insitutional Review Board.

Consent for publication

Additional informed consent and informed consent to publish was waived by the Insitutional Review Board.

\section{Competing interests}

MW is a part time employee of Philips Health Systems Switzerland. The authors declare they have no conflict of interest.

\section{Author details}

${ }^{1}$ Laboratory of Translational Nutrition Biology, Department of Health Sciences and Technology, 8603 ETH Zürich, Schwerzenbach, Switzerland. ${ }^{2}$ Department of Ophthalmology, Cantonal Hospital Winterthur, Brauerstrasse 15, 8401 Winterthur, Switzerland. ${ }^{3}$ Department of Radiology, Cantonal Hospital Winterthur, Brauerstrasse 15, 8401 Winterthur, Switzerland. ${ }^{4}$ Faculty of Medicine, University of Zürich, Zürich, Switzerland. ${ }^{5}$ Philips Health Systems, Zürich, Switzerland.

Received: 3 June 2019 Accepted: 11 December 2019

Published online: 16 December 2019

References

1. Cook C, Foster P. Epidemiology of glaucoma: what's new? Can J Ophthalmol. 2012;47(3):223-6. https://doi.org/10.1016/j.jcjo.2012.02.003.

2. Chen PP. Blindness in patients with treated open-angle glaucoma. Ophthalmology. 2003;110(4):726-33.

3. Peters $D$, Bengtsson $B$, Heijl A. Lifetime risk of blindness in open-angle glaucoma. Am J Ophthalmol. 2013;156(4):724-30. https://doi.org/10.1016/j. ajo.2013.05.027.

4. Weinreb RN, Khaw PT. Primary open-angle glaucoma. Lancet. 2004; 363(9422):1711-20.

5. Quigley HA. Neuronal death in glaucoma. Prog Retin Eye Res. 1999;18(1):39-57.

6. Quigley HA. Glaucoma Lancet. 2011;377(9774):1367-77. https://doi.org/10. 1016/S0140-6736(10)61423-7.

7. Quigley HA, Addickes EM, Green WR, Maumenee AE. Optic nerve damage in human glaucoma. II. The site of injury and susceptibility to damage. Arch Ophthalmol. 1981;99(4):635-49.

8. Tamm ER, Ethier CR. Lasker/IRRFInitiative on astrocytes and glaucomatous Neurodegeneration participants. Biological aspects of axonal damage in glaucoma: a brief review. Exp Eye Res. 2017;157:5-12. 
9. Killer HE. Compartment syndromes of the optic nerve and open-angle Glaucoma. J Glaucoma. 2013;22:S19-20.

10. Killer HE, Jaggi GP, Miller NR. Optic nerve compartment syndrome. Acta Ophthalmol. 2011;89(5):e472

11. Killer HE, Jaggi GP, Flammer J, Miller NR, Huber AR. The optic nerve: a new window into cerebrospinal fluid composition? Brain. 2006;129:1027-30.

12. Stowell C, Burgoyne CF, Tamm ER, Ethier CR. Lasker/IRRF initiative on astrocytes and glaucomatous Neurodegeneration participants. Biomechanical aspects of axonal damage in glaucoma: a brief review. Exp Eye Res. 2017;157:13-9.

13. Miglior S (2007) Risk factors for development of Glaucoma. European ophthalmic review. 2007, doi:https://doi.org/10.17925/EOR.2007.00.00.10.

14. Flammer J, Orgül S, Costa VP, Orzalesi N, Krieglstein GK, Serra LM, et al. The impact on ocular blood flow on glaucoma. Prog Retin Eye Res. 2002;21:359-93.

15. Schuman JS, Hee MR, Puliafito CA, Wong C, Pedut-Kloizman T, Lin CP, et al. Quantification of nerve fiber layer thickness in normal and glaucomatous eyes using optical coherence tomography. Arch Ophthalmol. 1995;113(5): 586-96.

16. Wu H, de Boer JF, Chen TC. Diagnostic capability of spectral-domain optical coherence tomography for glaucoma. Am J Ophthalmol. 2012; 153(5):815-26 e812.

17. Kuang TM, Zhang C, Zangwill LM, Weinreb RN, Medeiros FA. Estimating lead time gained by optical coherence tomography in detecting glaucoma before development of visual field defects. Ophthalmology. 2015;122(10):2002-9.

18. Mwanza JC, Warren JL, Budenz DL. Ganglion cell analysis study G. combining spectral domain optical coherence tomography structural parameters for the diagnosis of glaucoma with early visual field loss. Invest Ophthalmol Vis Sci. 2013;54(13):8393-400.

19. Diniz-Filho A, Abe RY, Zangwill LM, Gracitelli CP, Weinreb RN, Girkin CA, et al. Association between intraocular pressure and rates of retinal nerve Fiber layer loss measured by optical coherence tomography. Ophthalmology. 2016;123(10):2058-65.

20. Geurts JJ, Pouwels PJ, Uitdehaag BM, Polman CH, Barkhof F, Castelijns JA. Intracortical lesions in multiple sclerosis: improved detection with 3D double inversion-recovery MR imaging. Radiology. 2005;236:254-60.

21. Wattjes MP, Lutterbey GG, Gieseke J, Träber F, Klotz L, Schmidt S, Schild HH. Double inversion recovery brain imaging at $3 \mathrm{~T}$ : diagnostic value in the detection of multiple sclerosis lesions. AJNR Am J Neuroradiol. 2007;28:54-9.

22. Thompson AJ, Banwell BL, Barkhof F, Carroll WM, Coetzee T, Comi G, et al. Diagnosis of multiple sclerosis: 2017 revisions of the McDonald criteria. Lancet Neurol. 2018;17:162-73.

23. Sartoretti T, Sartoretti E, Rauch S, Binkert C, Wyss M, Czell D, SartorettiSchefer $\mathrm{S}$. How common is signal-intensity increase in optic nerve segments on $3 \mathrm{D}$ double inversion recovery sequences in visually asymptomatic patients with multiple sclerosis? AJNR Am J Neuroradiol. 2017;38(9):1748-53.

24. Wax MB, Gülgün T. Neurobiology of glaucomatous optic neuropathy. Diverse cellular events in Neurodegeneration and Neuroprotection. Mol Neurobiol. 2002;26(1):45-55.

25. Williams PA. Marsh-Armstrong N, Howell GR, Lasker/IRRF initiative on astrocytes and glaucomatous Neurodegeneration participants. Neuroinflammation in glaucoma: a new opportunity. Exp Eye Res. 2017; 157:20-7.

26. Howell GR, Soto I, Libby RT, John SW. Intrinsic axonal degeneration pathways are critical for glaucomatous damage. Exp Neurol. 2013;246:54-61.

27. Abbott CJ, Choe TE, Borgoyne CF, Cull G, Wang L, Fortune B. Comparison of retinal nerve Fiber layer thickness in vivo and axonal transport after chronic intraocular pressure elevation in young versus older rats. PLoS One. 2014; 9(12):e114546.

28. Chung HK, Harris A, Evans DW, Kagemann L, Garzozi HJ, Martin B. Vascular aspects in the pathophysiology of glaucomatous optic neuropathy. Surv Ophthalmol. 1999:43(Suppl. 1):S43-50.

29. Chidlow G, Ebneter A, Wood JPM, Casson RJ. The optic nerve head is the site of axonal transport disruption, axonal cytoskeleton damage and putative axonal regeneration failure in a rat model of glaucoma. Acta Neuropathol. 2011;121(6):737-51.

30. Crish SD, Sappington RM, Inman DM, Horner PJ, Calkins DJ. Distal axonopathy with structural persistence in glaucomatous neurodegeneration. Proc Natl Acad Sci U S A. 2010;107(11):5196-201.
31. Bendszus M, Wessig C, Solymosi L, Reiners K, Koltzenburg M. MRI of peripheral nerve degeneration and regeneration: correlation with electrophysiology and histology. Exp Neurol. 2004;188:171-7.

32. Iba-Zizen MT, Istoc A, Cabanis EA. Que penser des resultats d'exploration par IRM des patients atteints de glaucoma? J Fr Ophthalmol. 2008;31(6):2524-8.

33. Lee JY, Kwon HJ, Park SJ, Yoo C, Kim YY, Kim EY. Signal alteration in the optic nerve head on 3D T2-weighted MRI: a potential neuroimaging sign of glaucomatous optic neuropathy. Curr Eye Res 2018;43(3):397-405. https://doi.org/10.1080/02713683.2017.1399426.

\section{Publisher's Note}

Springer Nature remains neutral with regard to jurisdictional claims in published maps and institutional affiliations.
Ready to submit your research? Choose BMC and benefit from:

- fast, convenient online submission

- thorough peer review by experienced researchers in your field

- rapid publication on acceptance

- support for research data, including large and complex data types

- gold Open Access which fosters wider collaboration and increased citations

- maximum visibility for your research: over $100 \mathrm{M}$ website views per year

At BMC, research is always in progress.

Learn more biomedcentral.com/submissions 